\title{
Return to work after spinal cord injury: A review of recent research
}

\author{
Satoko Yasuda, Paul Wehman, Pamela Targett*, David X. Cifu and Michael West \\ Department of Physical Medicine and Rehabilitation, Medical College of Virginia, Virginia Commonwealth \\ University, Richmond, VA, USA
}

\begin{abstract}
This manuscript reviews recent research on return to work (RTW) for individuals who sustain spinal cord injury (SCI), including the effects of demographics variables, occupational characteristics, workplace accommodations, quality of life, physical functional limitations, and other variable. Demographic variables that influence RTW for persons with SCI include age at injury onset, chronological age, gender, education, ethnicity, marital status, and per-injury work intensity. Others include satisfaction, and adjustment to sustaining SCI. In an effort to enhance employment opportunities for individuals with disabilities including SCI, Ticket to Work Incentive Improvement Act of 1999 (TWILA) has been passed by Congress and some states have begun implementing targeted initiatives through the State Partnership Systems Change Initiatives (SPI). Future research directions are recommended in light of recent legislative initiatives.
\end{abstract}

Keywords: Spinal cord injury, employment, return to work, quality of life

\section{Introduction}

Vocational capacity, employment, and the opportunity to advance in a career are major determinants of success in American society. Society often defines us by our earning power, the type of work that we do, the regularity with which we are employed, the type of environment that we work in, and our long-term work potential. America is a capitalist society, a country that expects people to be productive in work.

In an effort to ease the entry of individuals with disabilities into the workforce, federal legislative initiatives have been enacted, such as the Americans with Disabilities Act (ADA: PL 101-336) that was passed in 1990. Structural changes in the American economy, advancement in rehabilitation technology, changes in social attitudes, and increase in public expenditure for employment services have occurred, all of which

\footnotetext{
*Address for correspondence: Rehabilitation Research and Training Center, Virginia Commonwealth University, 1314 West Main Street, P.O. Box 842011, Richmond, VA 23284-2011, USA. Tel.: +1 804828 1851; Fax: +1 804828 2193; E-mail: psherron@ atlas.vcu.edu.
}

should present more favorable employment opportunities for individuals with disabilities. However, the unemployment rate continues to remain high for individuals with disabilities, including those with spinal cord injury (SCI).

In addition to affecting the individuals with disabilities, unemployment affects society in numerous ways. High unemployment rate presents a significant social burden due to increase in the expenditures associated with benefits such as unemployment insurance and Social Securities disability benefits such as Supplemental Security Income (SSI) and Social Security Disability Income (SSDI). In September 1999, nearly 4.9 million workers with disabilities were receiving SSDI benefits and additional 3.6 million working age adults were receiving SSI benefits, a combined total of 8.6 million SSI/SSDI beneficiaries [53]. This represents an increase of over $10 \%$ in just five years. The average age of SSI/SSDI beneficiaries has declined in recent years and it is true that these younger individuals are likely to remain on the rolls for extended periods of time. It is even more discouraging that less than, one half of one percent of SSI/SSDI beneficiaries leaves the disability rolls and returns to work [64]. 
Employment outcome after SCI is an increasingly important issue to consider in light of improved survival rates following injury. According to the National Spinal Cord Injury Statistical Center [45], there are approximately 10,000 new cases each year, not including those who die at the scene of the accident. The number of people in the United States who have a SCI is estimated to be between 183,000 and 230,000. Due to advances in the medical field, more and more people are expected to survive this type of injury. The purpose of this article is to review recent literature on employment outcomes for individuals with SCI, including the effects of demographics variables, occupational characteristics, workplace accommodations, quality of life, physical functional limitations, and other variables, and to recommend future research directions in light of recent legislative initiatives that are implemented in an effort to enhance employment opportunities for individuals with SCI.

\section{Return to work incidence and occupations}

There have been numerous studies that have examined employment after SCI. However, employment rates vary considerably, depending on the study methodology. In literature reviews by Trieschmann [60] and Athanasou et al. [1], the employment rates range from $13 \%$ to $48 \%$ and $13 \%$ to $69 \%$, respectively. Other studies report similar broad ranges [7, $9-11,13,23,30,32,34,35,38,43,44,63]$. One reason for the variability may due to differences in the operational definition of employment being used. Studies that use narrow definitions of employment include only those working for pay or those who are self employed [27, 38], while studies that use broader definition include homemaker and students as well $[10,11]$. Another reason may be the difference in time after injury when the study was conducted since employment rates improve with increasing time after injury [30]. It is reported that the employment rate increased with a greater number of years after injury $[35,38]$.

Employment rates decrease dramatically when comparing pre-and post-injury rates. Approximately threequarters of those sustaining SCI were employed preinjury $[35,38]$. Of those who returned to work, more started new jobs rather than returning to their former employment [2]. However, those who returned to previous jobs did so much earlier than those who found new work $[2,30]$. Between $35 \%$ and $56 \%$ of those sustaining SCI were employed at some point since their in- jury $[18,35,38]$. Common occupations included: clerical, office, administrative, professional and technical jobs $[2,16,18]$. The majority of individuals were working with computers rather than in occupations that involved heavy manual labor [41]. No relationship was identified between pre- and post-injury employment status. However, those employed pre-injury demonstrated a lower mean time to return to work programs [18]. In addition, employment at time of injury was associated with a greater probability of post-injury employment, although this was limited to the first few years post-injury [39].

Castle [2] reported that, while occupations of persons with SCI varied over numerous employment categories pre-injury, a shift towards administrative, clerical and finance was commonly observed post-injury. Those who returned to work which involved the same level of physical intensity as pre-injury tended to work part-time [41]. It is probable that the difficulty in physical adjustment and the lack of stamina resulting from their injury did not allow them to meet the demands necessary to work full-time.

\section{Demographics and injury severity}

Gender does not seem to be significantly associated with return to work $[2,23,38,42]$. However, a significant relationship between gender and type of work has been identified. Men were twice as likely as women to be in paid employment, whereas women were more likely to be engaged in a non-paid productive role which include volunteers, full and part-time students, and homemakers [69]. Women who were employed, postinjury women and those who had been injured fewer years worked fewer hours [39]. When non-competitive employment, such as homemaking, volunteering, and students were included, women were more likely to be in either paid or unpaid productive roles [69].

Race was significantly related to employment status. Caucasians were more likely to be working postinjury than minorities [23,27,38,69]. James et al. [27] examined return to work among African-Americans and Caucasians. African-American females were more than twice as likely to obtain employment as AfricanAmerican males. Caucasian men were more likely than Caucasian women to obtain competitive employment. Age and education were also predictors of employment for both African-Americans and Caucasian subgroups. Those injured between the ages 46 and 61 were least 
likely to return to work. Education was a significant predictor, especially for African-Americans.

Several studies have examined the relationship between returning to work and the type of impairment. Five studies investigated the relationship between employment, race, and gender $[10,11,27,35,38]$. The studies that included only those who were competitively employed $[27,35,38]$ found that Caucasians were more likely to be working with mixed patterns for gender, with one study [2] suggesting an interaction between race and gender. Other studies that used a broader definition of employment included those who were employed, self employed, homemaker and students [10, 11] found that when homemakers were classified with the employed group, those who were Caucasian and female were more likely to return to work.

Age at injury onset appears to be most important for return to work [38]. Krause et al. [38] divided the participants into five groups for age at injury onset: younger than 18 years, to 25 years, 26 to 35 years, 36 to 45 years, and older than 45 years. Age at injury onset was significantly related to both current employment status and employment status since injury. The highest current employment rate was for those injured before the age of $18(69 \%)$ with the rate decreasing to $45 \%$ over the next three groups and employment rate of only $9 \%$ for those injured after 45 years. Older age at injury is negatively correlated with post-injury employment $[1,2,10,11,23,29,30,38,46]$ with the 16-30 age group having the highest employment rate [2] and 51 to 60 year group having the lowest [2,29].

Level of education has been consistently reported to be positively correlated to return to work $[2,11,23,30$, $34,38,46,57,69$ ]. Krause [30] found that nearly $95 \%$ of all persons with 16 or more years of education had worked at some point post-injury [30]. El Ghahit et al. [17] indicate that post-injury education was related to return to work. Education not only reflects higher socioeconomic status [42] but also increases the range of jobs to which an individual may return [23]. People with functional limitations are more likely to return to positions that require less physical labor.

Several studies have examined the relationship between returning to work and injury severity. Injury severity is classified into four groups based on injury level and completeness of injury: complete quadriplegia, incomplete quadriplegia, complete paraplegia, and incomplete paraplegia. Relationship between returning to work and injury severity have not been reported [38, ?]. Some studies have reported that individuals with paraplegia and/or incomplete legions were more likely to be employed $[2,10,17,35,55]$ while other studies have not linked injury severity with employment [8]. El Ghahit et al. [17] reported that although individuals with quadriplegia were less likely to obtain employment, they were equally able to sustain employment. Injury severity was a less important determinant of return to work for African-Americans than for Caucasians [27]. The author infers this to the differences in etiology of injury. Intentional injuries secondary to gunshot wounds are much more common among African Americans with paraplegia than among whites with paraplegia [20,55]. Persons who sustain gunshot wounds in many cases may have poorer premorbid adjustment and are less motivated to seek employment than those with other injury etiology.

Individuals who were employed had more clearly defined vocational goals and more positive selfperceptions than those who were unemployed. In general, more problems were reported by those unemployed [8]. It is interesting to note the difference in the reported problems that they experience when considering work after injury between those employed and those unemployed. Both groups reported accessibility, lack of benefits, transportation and physical limitations as being problems. Those employed reported lack of stamina and confidence, and low morale as problems while those unemployed reported lack of skills, need for retraining, and finding new careers. Persons with tetraplegia felt that they had to rely on others for punctuality and personal care [2].

The most frequently reported reasons for not working were inability to physically perform the same type of work post-injury $(60 \%)$ followed by poor health, stamina or endurance $(28 \%)$, loss of benefits $(28 \%)$, did not feel physically capable of working $(27 \%)$ and inaccessibility of the workplace $(23 \%)$. Problems of vocational decision-making included lack of information about employment opportunities, uncertainty about vocational and educational abilities, lack of knowledge of occupations and uncertainty in many areas of life [8]. Gender, race, age, and level of injury were all associated with these different reasons [36].

Recently, Hess et al. [23] found that the relative importance of many of the variables utilized in predicting return to work vary over time intervals. The ability of the Motor Index Score in combination with demographic variables was examined to predict return to work during three years period for individuals with SCI. The most important predictors of return to work were education, MIS, race, and age of injury onset. However, race was more significant at year 3 than at year 1 , 
and marital status was significant at year 1 and 2 , but not at 3. They suggested that return to work after SCI is a dynamic process and their ability to work changes over time.

In summary, a review of both the demographic and injury severity and completeness literature indicates that the most successful employment outcomes were obtained by Caucasian women, persons younger than 29 years old at onset of injury, persons with incomplete and less severe injuries, those having lived more years with SCI, and persons who had completed at least 16 years of education. The least successful outcomes were found in minority men, persons over 50 years old at injury, persons with complete quadriplegia, and persons with fewer than 12 years of education (Table 1).

\section{Other factors}

In addition to demographic and neurologic completeness characteristics that have been shown to impede return to work after SCI, other factors have been found to have influence on their life and to successful return to work. Health was a major limiting factor to employment, as well as the lack of suitable jobs [18].

It has been suggested that persons with SCI are able to engage in competitive employment if appropriate accommodations that meet their needs are provided, such as product-related and worksite modifications. Dowler et al. [16] reported that nearly three-quarters of individuals required some type of accommodation to maintain or improve their productivity. Inge et al. $[25,26]$ also discussed the utilization of effective assistive technology supports as one of the challenges that influence employment success. In addition, addressing transportation needs and providing training so that individuals can get to and from work is critical for ensuring the individual's self-determination in employment, housing and social/recreational outlets [67]. These may include supports and accommodations to eliminate both the physical barriers of the workplace and psychological barriers in the worker, thus supporting both their physical and mental health.

A positive relationship has been found between life satisfaction and adjustment after SCI and employment status $[8,29,31,33,39]$. Those employed were behaviorally more active, had fewer medical treatments, completed more years of education, perceived themselves to have fewer problems, were more satisfied with their lives, and rated their overall adjustment higher than those who were unemployed [29,31]. Termination of employment also seems to be associated with declines in adjustment. The results were more consistent with becoming employed leading to better adjustment, rather than the reverse [33]. There was a strong association of both education and employment with quality of life after SCI [38].

Successful reintegration, which includes return to work, is influenced by the ability of the individual to exercise control of their environment and make personal choices. Their ability to grasp and develop new skills is also an important factor. Participation in community events and activities decreased post-injury, due to lack of support and assistance with transportation, finances and overcoming architectural barriers. As a result of decreased mobility and independence, social integration was negatively affected $[56,62,65]$.

Cifu et al. [3] indicate that although younger people are more likely be more severely injured at admission and discharge, they are more likely to have a wider social support network including parents, siblings, spouses, and friends who are all physically capable to take care. This may explain why younger patients are least likely to be discharged to an institutional setting [3-5], which is consistent with previous findings $[12,48]$. Spinal cord caregivers experience tremendous amount of both physical and emotional distress that are ongoing and having long-term effects [28]. It becomes critical to provide support to them as well as to those sustaining SCI. Since persons with SCI require social support for community re-entry, this will indirectly enhance the likelihood of higher RTW outcomes.

\section{Quality-of-life}

Quality-of-life is associated with meeting individual needs, controlling one's environment, and having opportunities to make choices. Quality-of-life issues for SCI population have recently begun to be examined $[6,19,54,66]$. Results indicated that quality-of-life of individuals with SCI were significantly lower than for a normative population [68]. Individuals sustaining SCI are faced with physical, emotional, financial, and vocational changes. These problems are often complex and profound and therefore can have a negative effect on one's quality-of-life and satisfaction especially with community reentry and employment [14]. Some studies have utilized quality-of-life to measure success of employment services for individuals with disabilities $[24,49,50]$. Results indicated improved quality-of- 
Table 1

Summary of studies on factors influencing RTW for persons with spinal cord injury (1995-2001)

\begin{tabular}{|c|c|c|c|c|c|}
\hline & $\mathrm{N}$ & $\begin{array}{l}\text { Age } \\
\text { Years }\end{array}$ & Completeness/level of injury & $\begin{array}{l}\text { Employment } \\
\text { Rate }(\%)\end{array}$ & Significant variables \\
\hline $\begin{array}{l}\text { Hess et al., } \\
2000[22]\end{array}$ & $\begin{array}{l}\text { Year } 1=1857 \\
\text { Year } 2=1486 \\
\text { Year } 3=1177\end{array}$ & $18-65$ & & $\begin{array}{l}\text { Year } 1=21 \\
\text { Year } 2=21 \\
\text { Year } 3=23\end{array}$ & $\begin{array}{l}\text { Year } 1=\text { age, education, motor } \\
\text { index score (MIS), marital status, } \\
\text { ethnicity, gender } \\
\text { Year } 2=\text { education, MIS, marital } \\
\text { status, ethnicity } \\
\text { Year } 3=\text { education, MIS, ethnicity }\end{array}$ \\
\hline $\begin{array}{l}\text { Tomassen } \\
\text { et al., } 2000 \\
{[58]}\end{array}$ & 234 & $\begin{array}{l}18-65 \\
\text { Mean } 40\end{array}$ & $\begin{array}{l}22 \% \text { complete tetraplegia } \\
20 \% \text { incomplete } \\
29 \% \text { complete paraplegic } \\
29 \% \text { incomplete }\end{array}$ & 37 & $\begin{array}{l}\text { age, gender, education, pre-injury } \\
\text { work intensity, Barthel Index }\end{array}$ \\
\hline $\begin{array}{l}\text { Krause } \\
\text { et al., } 1999 \\
{[38]}\end{array}$ & 3756 & Mean 38.6 & $\begin{array}{l}43.5 \% \text { paraplegic } \mathrm{ABC} \text { injuries } \\
26.2 \% \text { low tetraplegic } \mathrm{C} 5-\mathrm{C} 8 \\
\mathrm{ABC}\end{array}$ & $\begin{array}{l}\text { Follow-up Year } \\
1=13.8 \\
2=18.1 \\
5=25.8 \\
10=35.1 \\
15=38.4 \\
20+=39.3\end{array}$ & $\begin{array}{l}\text { employment status at injury, eth- } \\
\text { nicity, etiology, age at injury onset, } \\
\text { chronological age, injury level by } \\
\text { Frankel grade, education }\end{array}$ \\
\hline $\begin{array}{l}\text { Krause } \\
\text { et al., } 1998 \\
{[37]}\end{array}$ & $\begin{array}{l}1032 \\
\text { Midwestern } \\
=597 \\
\text { Southeastern } \\
=435\end{array}$ & Mean 42.4 & $55 \%$ cervical injuries & $\begin{array}{l}36 \\
\text { Midwestern }=50 \\
\text { Southwestern }=26\end{array}$ & $\begin{array}{l}\text { Midwestern = age at injury onset, } \\
\text { chronological age, years since in- } \\
\text { jury, education } \\
\text { Southeastern = chronological age, } \\
\text { years since injury, level and com- } \\
\text { pleteness of injury, education, gen- } \\
\text { der and race }\end{array}$ \\
\hline $\begin{array}{l}\text { Engel et al., } \\
1998 \text { [18] }\end{array}$ & 83 & $\begin{array}{l}20-83 \\
\text { Mean } 44.7\end{array}$ & $\begin{array}{l}20 \% \text { complete quadriplegia } \\
23 \% \text { incomplete quadriplegia } \\
41 \% \text { complete paraplegia } \\
16 \% \text { incomplete paraplegia }\end{array}$ & 33 & Compensation entitlement \\
\hline $\begin{array}{l}\text { Krause } \\
\text { et al., } 1997 \\
{[36]}\end{array}$ & 362 & Mean 38.8 & Paraplegic, quadriplegic & 25 & $\begin{array}{l}\text { gender, ethnicity, age at time of } \\
\text { study, age at injury onset, ed- } \\
\text { ucation, general satisfaction, ca- } \\
\text { reer satisfaction, skills deficit, } \\
\text { adjustment }\end{array}$ \\
\hline $\begin{array}{l}\text { Krause, } \\
1996[32]\end{array}$ & $\begin{array}{l}\text { Time } 1=256 \\
\text { Time } 2=142\end{array}$ & $\begin{array}{l}\text { Mean } 20.5 \\
\text { Mean } 40.5 \\
<60\end{array}$ & $66 \%$ quadriplegic & $\begin{array}{l}\text { Stable Employment } \\
=33 \\
\text { Positive Transition } \\
=22\end{array}$ & $\begin{array}{l}\text { Time } 1=\text { activity, economic dis- } \\
\text { satisfaction } \\
\text { Time } 2=\text { activity, economic } \\
\text { dissatisfaction }\end{array}$ \\
\hline $\begin{array}{l}\text { Krause } \\
\text { et al., } 1996 \\
{[34]}\end{array}$ & 362 & Mean 39 & $\begin{array}{l}53 \% \text { quadriplegic } \\
48 \% \text { complete injuries }\end{array}$ & 25 & $\begin{array}{l}\text { Gender, gender and race, age } \\
\text { education }\end{array}$ \\
\hline
\end{tabular}

life for persons participating in competitive employment.

There are several variables that affect the degree of quality-of-life of individuals with SCI. Both education and employment had strong association with qualityof-life post-injury [29-31,33,37]. The level or the extent of SCI is not a predictor of life satisfaction [14, 51]. Wehman et al. [66] examined work satisfaction variables of both employed and unemployed persons with SCI. Majority of persons employed indicated that they would either change jobs or some employment variable such as duties, supervisor, or hours worked. Surprisingly, transportation to and from work was not a concern for them. Individuals that were employed reported factors such as ongoing health problems, lack of transportation, and impact on disability benefits if employed. Individuals with SCI continue to have issues and challenges they have to adjust to and the need for rehabilitation does not end after hospital discharge [66]. Since employment is important in our society not just in terms of financial security but also for self-esteem, independence, social relationships, self worth, and personal identity [47], it becomes critical to provide ongoing assistance in addition to effective rehabilitation programs. This would enable persons with SCI to return to work and as a result enhance their quality-of-life. 


\section{Physical functional limitations}

Tomassen et al. [59] investigated the relationship between return to competitive employment and the physical intensity of pre-injury employment. They found that of the $37 \%$ who returned to work, $25 \%$ and $21 \%$ of those with heavy and strenuous physical work preinjury, respectively, returned to work. Persons with less physically intense occupations pre-injury were more likely to return to work. It has been suggested that in returning to physically intense occupations, there may be difficulties in adapting the work site. In addition, they may be less motivated to choose a less physically intense occupation, such as administrative work, which may require higher level of education. individuals who are employed reported that functional limitation, such as upper and lower extremity functions and mobility, affected them in terms of moving about in the workplace and getting to and from work [16]. However, contradictory findings have been reported in terms of the relationship between the level of injury and return to work. While some have noted level of injury as a strong predictor of return to work $[15,17,22,55]$, others did not support this view [18,29,30,38]. Similarly, Castle [2] found completeness of the injury, whether individuals were paraplegic or tetraplegic, as a predictor of return to work [2], while Engle et al. [18] and Krause [30] reported that the only significant difference between individuals with paraplegia and tetraplegia was that individuals with paraplegia were more likely to return to their pre-injury jobs than those with tetraplegia.

Hess et al. [23] evaluated the ability of Motor Index Score (MIS) to predict return to work. MIS has been found to be useful in predicting self-care abilities during rehabilitation [40]. MIS was a significant predictor of return to work. Hess et al. [23] indicate that higher MIS can be associated with higher physical abilities, which therefore increasing the likelihood of return to work. These studies suggest that for persons with SCI, barriers to return to work are created by their physical functioning limitations. These limitations all prevent full participation and independence at the work site, which may further lead to a low satisfaction level or having to work part-time.

Trupin and Yetin [61] examined the differences in the qualitative aspects of employment, including job content, job satisfaction, and expectations of future employment between individuals with and without disabilities. Their use of the term "disability" does not conform to the definition used by the Americans with Disabilities Act (ADA). Instead, they use functional limitation as a proxy for disability status. Many of the individuals sustaining SCI have limited functions, and therefore can be deemed as having considerable "functional limitation", as used in their report. Results indicated the following:

1) The largest difference in the employment experience of individuals with and without physical functional limitation is in their labor force participation rate.

2) Among individuals who are in the labor force, those with significant physical functioning limitation are likely to be employed part-time rather than full-time. They are less satisfied with their current job, less optimistic about their future prospects, and less likely to report having autonomy at work.

3) Among individuals who are unemployed, threequarters of those with many of functional limitations report that these limitations created a major problem in their life, and are less likely to report a desire to work. This is a landmark study, in that it creates a compelling rationale for this employment-based SCI Model System.

Other type of support to promote return to work might be to provide compensation, sufficient enough but not too much so as not to inhibit the motivation to return to work. Compensation entitlement, which includes compensations such as motor vehicle and worker' compensation, was found to be a limiting factor in returning to work [18]. The percentage of individuals entering the workforce after injury was higher for those who were not entitled to any form of compensation compared to those receiving compensation $(51 \%$ and $23 \%$ respectively). Tomassen et al. [59] also indicated that the high financial compensation in Netherlands, which equals to $70 \%$ of their last earned wage, might result in the high number of people who do not return to work post-injury.

Obstacles reported by individuals with disabilities that prevent them from returning to or entering the workforce include inability to obtain sufficient health care insurance to enable them to live and work independently, financial disincentives to work in current benefit programs, and inability to access effective employment training and placement services. In addition, they have difficulty obtaining employment due to lack of knowledge in terms of eligibility and services that would assist them in obtaining employment to which they are entitled. It is critical that access to medical and rehabilitation services are maintained and ensured. 
Medical coverage availability is a life or death situation for the majority of persons sustaining SCI due to ongoing medical care requirement that is in many instances financially demanding and challenging. If they do not understand their benefit eligibility, the pros and cons of their situation and options, and are not convinced that returning to work would be worthwhile, persons sustaining SCI will most likely not risk their current situation as SSI/SSDI beneficiaries by returning to work and having the risk of losing benefits.

\section{Research implications}

It is notable that the majority of the studies cited here have been conducted within the previous decade, postADA. Under the ADA, most workplaces in the United States are prohibited from discriminating against qualified individuals with disabilities and are required to provide necessary accommodations. There are judicial remedies to combat outright discrimination and failure to accommodate if the prospective worker chooses to utilize them. However, recent research shows that many individuals with SCI either fail to re-enter the workforce or choose not to, and that physical limitations related to the injury contribute to these situations. There is a need to investigate the knowledge and use of rights and remedies on the part of individuals with SCI to self-advocate for employment and accommodations, as well as self-reported reasons why individuals with SCI choose not to attempt to work.

There are other rather critical gaps in the employment research which a review of these $25+$ empirical studies published over the past decade reveal. Most notably;

1. Very few of the studies are longitudinal, that is, there has not been long term tracking over time of the same group of individuals' vocational outcomes and employment histories. Thus we have little insight into the progression of return to work over time, as when individuals enter the workforce in part-time or low-impact work and progresses to more demanding work, or more hours per day or week.

2. There is a lack of breadth in the vocational data collected. Significantly more information is needed regarding vocational barriers, workplace environment, career advancement opportunities, types of employment attempted (i.e., telework, self-employment, etc.) and job retention rates.
3. Few studies document clinical intervention strategies for accelerating employment rates, expanding productivity, opening up new career opportunities, or making people with SCI more employable. This is a major gap that needs to be addressed.

4. Very few of the studies address issues of individual job satisfaction, job preferences, role of family influences need and availability of specialized transportation services, or personal assistants.

The impact of health care benefits, Social Security disability policy, private disability policy, Vocational Rehabilitation and other key policy and legislative issues have not been studied in the context of SCI. For Example, fear of losing disability benefits, particularly health care, is known to keep many Social Security disability recipients from re-entering the workforce [52]. To combat this fear, Congress and the Social Security Administration have instituted a number of work incentives to allow disability beneficiaries to either (a) work and retain benefits, or (b) ease the transition to self-sufficiency. To what extent do disability benefits and work incentives impact individuals with SCI across different age ranges and functional limitations?

The Ticket to Work and Work Incentives Improvement Act of 1999 (TWWIIA) was passed by Congress to address the low employment rate for disability beneficiaries. Among the Act's provisions are: (1) the use of a "ticket" or voucher to increase choice and self-determination in return to work services; (2) allowing working beneficiaries to purchase health care through Medicaid or Medicare at reduced rates when employer-sponsored insurance is not available; and (3) a nationwide system of benefits planning and assistance providers who will counsel beneficiaries on the impact of different levels of earnings on benefits. As the TWWIIA initiatives unfold, there will be a need to examine the effects on motivation to re-enter the workforce following SCI (as well as other disabilities) and long-term workforce participation [58].

In an effort to enhance employment opportunities for individuals with disabilities, some states have begun implementing targeted initiatives through the State Partnership Systems Change Initiative (SPI). SPI is one of the efforts by the Federal Government in conjunction with the Presidential Task Force on the Employment of Adults with Disabilities to alleviate obstacles and to promote employment for SSI and SSDI beneficiaries. It is comprised of 18 state projects designed to identify, implement and evaluate innovative strategies that promote employment opportunities for SSI 
and SSDI beneficiaries, as well as recipients of other types of public supports. These initiatives vary considerably from state to state. However, major activities fall into the following activities: Medicaid-Buy-In Activities, Social Security Waiver, Benefit Planning and Assistance, One-Stop Career Centers, Interagency Collaborative Activities, Consumer Mentoring Activities, and Direct Employment Services. These initiatives address the problems that are reported to hinder return to work for persons with SCI. Through these initiatives, we may be able to determine effective supports that would benefit individuals with SCI returning to work.

\section{Conclusion}

As this literature review underscores, successful RTW following SCI is a complex interplay of injury severity, social and demographic issues, work conditions, and individual skills and motivation Prediction of RTW is challenging, given that presumably minor logistical factors can hinder or prohibit attempts to work. For example, an individual may have significant residual skins and a supportive and accommodating employer, but may require specialized transportation or personal assistance services that are unavailable where he or she resides. In addition, many individuals with SCI contradict the prediction model and success in returning to work seems to be against substantial odds.

Legislation has been passed in an effort to enhance employment opportunities for individuals with disabilities and targeted initiatives have been implemented through SPI. These initiatives address the problems that are reported to hinder RIW for those with SCI as well. Through these initiatives, effective supports that would benefit individuals with SCI returning to work may be determined.

\section{Acknowledgements}

This paper was partially supported by Grant \#HI33N 00015, funded by the United States Department of Education, and Grant \#H133B980036, funded by the United States Department of Education National Institute on Disability and Rehabilitation Research.

\section{References}

[1] J.A. Athanasou, D.J. Brown and G.C. Murphy, Vocational achievements following spinal cord injury in Australia, Disability Rehabilitation 18 (1996), 191-196.
[2] R. Castle, An investigation into the employment and occupation of patients with a spinal cord injury, Paraplegia 32 (1994), $182-187$.

[3] D.X. Cifu, R.T. Seel, J.S. Kreutzer, J. Marwitz, W.O. McKinley and D. Wisoe, Age, outcome, and rehabilitation costs after tetraplegia spinal cord injury, NeuroRehabilitation 12 (1999), 177-185.

[4] D.X. Cifu, M.E. Huang, S.A. Kolalowsky-Hayner and R.T. Seel, Age, outcome, and rehabilitation costs after paraplegis caused by traumatic injury of the thoracic spinal cord, conus medullaris, and cauda equina, Journal of Neurotrauma 16(9) (1999), 805-815.

[5] D.X. Cifu, R.T. Seel, J.S. Kreutzer and W.O. McKInley, A multicenter investigation of age related differences in lengths of stay, hospitalization charges, and outcomes for a matched tetraplegia sample, Archives of Physical Medicine and Rehabilitation 80 (1999), 733-740.

[6] K.S. Clayton and R.A. Chubon, Factors associated with quality of life of long-term spinal cord injured persons, Archives of Physical medicine and Rehabilitation 75 (1994), 633-638.

[7] N.M. Crewe and J.S. Krause, An eleven-year follow up of adjustment to spinal cord injury, Rehabilitation Psychology 35 (1990), 205-210.

[8] R. Crisp, Vocational decision making by sixty spinal cord injury patients, Paraplegia 30 (1992), 420-424.

[9] L. Cushman and J. Hasset, Spinal cord injury: 10 and 15 years after, Paraplegia 30 (1992), 690-696.

[10] M.J. DeVivo and P.R. Fine, Employment status of spinal cord injured patients 3 years after injury, Archives of Physical Medicine and Rehabilitation 63 (1982), 200-203.

[11] M.J. DeVivo, R.D. Rutt, S.L. Stover and P.R. Fine, Employment and spinal cord injury, Archives of Physical Medicine and Rehabilitation 68 (1987), 494-498.

[12] M.J. De Vivo, P.L. Kartus, R.D. Rutt, S.L. Stover and P.R. Fine, The influence of age at time of spinal cord injury on rehabilitation outcome, Archives of Neurology 47 (1990), 687691.

[13] M. De Vivo, S. Richards, S. Stover and B.Go, Spinal cord injury: Rehabilitation adds life to years, Western Journal of Medicine 154 (1991), 602-606.

[14] M.J. De Vivo and J.S. Richards, Community reintegration and quality of life following spinal cord injury, Paraplegia $\mathbf{3 0}$ (1992), 108-112.

[15] M.P. Dijkers, M.B. Abela, B.M. Gans and W.A. Gordon, The aftermath of spinal cord injury, in: Spinal cord injury: Clinical outcomes from the model system, S.L. Stover, J.A. De Lisa and G.G. Whiteneck, eds, Aspen Publishers, Gaithersburg, MD, 1995, pp. 185-209.

[16] D. Dowler, L. Batiste and E. Whidden, Accommodating workers with spinal cord injury, Journal of Vocational Rehabilitation 10 (1998), 115-122.

[17] A.Z. El Ghahit and R.W. Hanson, Educational and training levels and employment of the spinal cord injured patients, Archives of Physical Medicine and Rehabilitation 60 (1979), 405-406.

[18] S. Engel, G.S. Murphy, J.A. Athanasou and L. Hickey, Employment outcomes following spinal cord injury, International Journal of Rehabilitation Research 21(2) (1998), 223-229.

[19] R.L. Evans, R.D. Hendricks, R.T. Connis et al., Quality of life after spinal corrd injury: A critique and meta-analysis (19831992), Journal of American Paraplegia Society 17 (1993), 60-66.

[20] P.R. Fine, M.A. Stafford, J. M. Miller and S. L. Stover, Gunshot wounds of the spinal cord: A survey of literature and epi- 
demiologic study of 48 lesions in Alabama, Alabama Journal of Medical Sciences 13 (1976), 173-180.

[21] S.W. Fox, B.J. Anderson and W.O. McKinley, Case management and Critical pathways: Links to quality care for persons with spinal cord injury, American Rehabilitation 22(4) (1996), 20-25.

[22] W.O. Geisler, A.T. Jousee and M. Wynne-Jones, Vocational reestablishment of patients with spinal cord injury, Medical Service Journal Canada 22 (1966), 698-709.

[23] D.W. Hess, D.L. Ripley, W.O. McKinley and M. Tewksbury, Predictors for returning to work after spinal cord injury: A 3 year multicenter analysis, Archives of Physical Medicine and Rehabilitation 81 (2000), 359-363.

[24] K.J. Inge, D. Banks and P. Wehman, Quality of life for individuals who are labeled mentally retarded: Evaluation competitive employment versus sheltered workshop employment, Education and Training in Mental Retardation 23 (1988), 97104.

[25] K.J. Inge, P. Wehman, W. Strobel, D. Powell and J. Todd, Supported employment and assistive technology for persons with spinal cord injury: Three illustrations of successful work supports, Journal of Vocational Rehabilitation 10 (1998), 141152.

[26] K.J. Inge, P. Wehman, W. Strobel, J. Todd and P. Targett, Vocational outcomes for persons with severe physical disabilities: Design and Implementation of workplace supports, American Journal of Physical Medicine and Rehabilitation.

[27] M. James, M.J. DeVivo and J.S. Richards, Postinjury employment outcomes among African-American and white person with spinal cord injury, Rehabilitation Psychology 38 (1993), 151-164.

[28] S.A. Kolalowsky-Hayner and R. Kishore, Caregiver functioning after traumatic injury, NeuroRehabilitation 13 (1999), 27 33.

[29] J.S. Krause, The relationship between productivity and adjustment following spinal cord injury, Rehabilitation Counseling Bulletin 33(3) (1990), 188-199.

[30] J.S. Krause, Employment after spinal cord injury, Archives Physical Medicine and Rehabilitation 73(2) (1992), 163-169.

[31] J.S. Krause, Adjustment to life after spinal cord injury: A comparison among three participant group based on employment status, Rehabilitation Counseling Bulletin 35(4) (1992), 218-229.

[32] J.S. Krause, Longitudinal changes in adjustment after spinal cord injury: A 15 year study, Archives of Physical Medicine and Rehabilitation 73 (1992), 564-568.

[33] J.S. Krause, Employment after spinal cord injury: Transition and adjustment, Rehabilitation Counseling Bulletin 40 (1996), 244-255.

[34] J.S. Krause, Adjustment after spinal cord injury: A 9 year longitudinal study, Archives of Physical Medicine and Rehabilitation 78 (1997), 651-657.

[35] J.S. Krause and C.A. Anson, Employment after spinal cord injury: Relation to selected participant characteristics, Archives of Physical Medicine and Rehabilitation 77(8) (1996), 737743.

[36] J.S. Krause and C. A. Anson, Self-perceived reasons for unemployment cited by persons with spinal cord injury: Relationship to gender, race, age, and level of injury, Rehabilitation Counseling Bulletin 39 (1996), 217-227.

[37] J.S. Krause and C.A. Anson, Adjustment after spinal cord injury: Relationship to participation in employment or educational activities, Rehabilitation Counseling Bulletine 40 (1997), 202-214
[38] J.S. Krause, M. Sternberg, J. Maides and L. Lottes, Employment after spinal cord injury: Differences related to geographic region, gender, and race, Archives of Physical Medicine and Rehabilitation 79 (1998), 615-624.

[39] J.S. Krause, D. Kewman, M.J. De Vivo, F. Maynard, J. Coker, M.J. Roach and S. Ducharme, Employment after spinal cord injury: An analysis of cases from the model spinal cord injury systems, Archives of Physical Medicine and Rehabilitation 80(11) (1999), 1492-1500.

[40] R.B. Lazar, G.M. Yarkony, D. Ortolano, A.W. Heinemann, E. Perlow, L. Lovell et al., Prediction of functional outcome by motor capability after spinal cord injury, Archives of Physical Medicine and Rehabilitation 70 (1989), 819-822.

[41] R. Levi, C. Hulting and A. Seiger, The Stockholm spinal cord injury: Psychosocial and financial issues of the Swedish annual level-of-living survey in SPINAL CORD INJURY subjects and controls, Paraplegia 34 (1996), 152-157.

[42] E. MacKenzie, S. Shapiro, R. Smith, J. Seigel, M. Moody and A. Pitt, Factors influencing return to work following hospitalization for traumatic brain injury, American Journal of Public Health 77 (1987), 329-334.

[43] S.L. McShane and J. Karp, Employment following spinal cord injury: A covariance structure analysis, Rehabilitation Psychology 38 (1993), 27-40.

[44] G. Murphy et al., Labor force participation and employment among a sample of ustralian patients with a spinal cord injury, Spinal Cord 35 (1997), 238-244.

[45] National Spinal Cord Injury Statistical Center, Spinal cord injury: Facts and figures at a glance, National Spinal Cord Injury Statistical Center: Birmingham, Alabama, 2000.

[46] L. Noreau and R.J. Shephard, Return to work after spinal cord injury: The potential contribution of physical fitness, Paraplegia 30(8) (1992), 563-572.

[47] R.W. Rice, J.P. Near and R.G. Hunt, The job satisfactionlife satisfaction relationship: A review of empirical research, Basic Applied Social Psychology 1 (1980), 37-64.

[48] E.J. Roth, L. Lovell, A.W. Heinemann, M.Y. Lee and G.M. Yarkony, The older adult with a spinal cord injury, Paraplegia 30 (1992), 520-526.

[49] D. Sandow, L. Rhodes, D.M. Mank et al., Assuring quality in supported employment, Journal of Rehabilitation Administration 14 (1990), 20-25.

[50] R.L. Schalock, K.D. Keith, K. Hoffman et al., Quality of life: Its measurement and use, Mental Retardation 27 (1989), 2531.

[51] A. Sioesteen, C. Lundqvist, C. Blomstrand et al., The quality of life of three fuctional spinal cord injury subgroups in a Swedish community, Paraplegia 28 (1990), 467-488.

[52] Social Security Administration, SSI recipients who work. Available at http://www.ssa.gov/statistics/ssi_qrtly/index.html.

[53] Social Security Administration, Annual Statistical Supplement. Available at http://www.ssa.gov/statistics/Supplement/2000/.

[54] R. Stensman, Adjustment to traumatic spinal cord injury: A longitudinal study of self-reported quality of life, Paraplegia 32 (1994), 416-422.

[55] S.L. Stover and P.R. Fine, Spinal cord injury: the facts and figures, University of Alabama at Birmingham: Birmingham, AL, 1986.

[56] P.S. Targett, K. Wilson, P. Wehman and W.O. McKinley, Community needs assessment survey of people with spinal cord injury: An early follow-up study, Journal of Vocational Rehabilitation 10 (1998), 169-177. 
[57] M. Taricco, C. Colombo, R. Adone et al., The social and vocational outcome of spinal cord injury patients, Paraplegia 30(3) (1992), 214-219.

[58] Ticket to Work and Work Incentives Improvement Act of 1999. 42 U.S.C. 1305. P.L. 106-170. 106th Congress.

[59] P.C.D. Tomassen, M.W.M. Post and F.W.A. van Asbeck, Return to work after spinal cord injury, Spinal Cord 38 (2000), $51-55$.

[60] R. Trieschmann, Spinal cord injuries: The psychological, social, and vocational rehabilitation, 2nd ed., Demo Publications: New York, 1988.

[61] L. Trupin and E. Yelin, The employment experience of persons with limitations in physical functioning: An analysis of the 1996 California work and health survey. Disability Statistics Rehabilitation Research and Training Center, University of California: San Francisco, CA, 1999

[62] E. Turner, P. Wehman, J.F. Wallace, M.K. Webster, J. O’Bryan, S. O'Mara and W. Parent, Overcoming obstacles to community reentry for persons with spinal cord injury: Assitive technology, ADA and self-advocacy, Journal of Vocational Rehabilitation 9 (1997), 171-186.

[63] I. Ville and J.F. Ravaud, Work, non-work and consequent satisfaction after spinal cord injury, International Journal of Rehabilitation Research 19 (1996), 241-252.
[64] Virginia Commonwealth University Rehabilitation Research and Training Center on Workplace Supports, First year accomplishments of the State Partnership System Change Initiative (SPI), unpublished annual report: Richmond, VA, 2000.

[65] P. Wehman, K. Wilson, P. Targett, M. West, J. Bricout and W. McKinley, Removing transportation barriers for persons with spinal cord injuries: An ongoing challenge to community reintegration, Journal of Vocational Rehabilitation 13 (1999), 21-30.

[66] P. Wehman, K. Wilson, W. Parent, P. Sherron-Targett and W. McKinley, Employment satisfaction of individuals with spinal cord injury, American Journal of Physical Medicine and Rehabilitation 79(2) (2000), 161-169.

[67] M. West, T. Hock, K. Wittig and V. Dowdy, Getting to work: Training and support for transportation needs, Journal of Vocational Rehabilitation 10 (1998), 159-167.

[68] N. Westgren and R. Levi, Quality of life and traumatic spinal cord injury, Archives of Physical Medicine and Rehabilitation 79 (1998), 1433-1439.

[69] M. Young, W.G. Alfred, D.H. Rintala and K.A. Hart, Vocational status of persons with spinal cord injury living in the community, Rehabilitation Counseling Bulletin 37 (1994), 229-243. 